\title{
(2) Everything-as-a-Service (XaaS) in the World of aBe Technology and Trade
}

\author{
Apoorva Ganapathy \\ Senior Developer, Adobe Systems, San Jose, California, USA \\ E-mail for correspondence: apganapa@adobe.com
}

\begin{abstract}
This article is expected to extensively clarify what Everything As-A-Service means and how it is utilized to arrive at many customers across the globe. Curiously, it uses distributed computing in giving different types of administrations to its buyers. It was noted to help in the development and headway of organizations and smooth promoting of items. It was also noticed that the XaaS has various classes, which adds up to many of them, which a lot was painstakingly analyzed along with their different advantages and burdens in like-way. Some of them have models, which was adequately investigated considering how it may be put to use by the administrator to create wanted outcomes.
\end{abstract}

Keywords: XaaS, Service Infracture, Organizational Software, SECaaS, IaaS, Database

\section{INTRODUCTION}

The need to see how these web-driven terms function and work can't be over-accentuated, particularly as it identifies with item promoting, time and asset saving, and even productivity objectives. This article would divulge the different classifications of administrations cherished inside XaaS and how it is utilized at last.

\section{Everything As-A-SerVIce (XAAS)?}

XaaS came into utilization after specific advancements and developments were associated with organizations and merged to become productized. "Anything as an assistance" (XaaS) depicts an overall classification of administrations identified with distributed computing and far-off access. It perceives the immense number of items, apparatuses, and advances that are presently conveyed to clients as assistance over the web. Any IT capacity can be changed into help for significant business utilization. The aid is paid for in an adaptable utilization model as opposed to as a forthright buy or permit (Ganapathy, 2019a). XaaS use distributed computing rather than on location nearby programming to offer different types of assistance and arrive at clients. It gives you more extraordinary adaptability in maintaining your business on workers housed in a stockroom or even nearby. The XaaS business is developing and ought to be a developing concentration in future years to come. To say that it has been groundbreaking to the way organizations work would be putting it mildly (Ganapathy, 2016a). More organizations are going to XaaS to control and develop their ventures. The worldwide $\mathrm{XaaS}$ market is right now growing at an accumulate yearly development pace of around $26 \%$, and specialists foresee this pattern to proceed until at any rate 2025 .

\section{What Is the XaaS Model?}

XaaS organizations use distributed computing to convey their administrations to a considerable number of clients around the world. Their items are regularly online stages that are accessible consistently for clients to sign in. Clients will experience a simple to utilize workspace that is frequently housed directly in their program. In the wake of making changes or downloading information from this workspace, the program will send the solicitation to the stage. Regularly, the stage runs on premise workers, a cloud supplier, or an electronic organization. A XaaS step takes out the need to stress over working out broad on premise stockpiling, web administrations, equipment, or custom programming. It relies upon what administration the particular XaaS organization is advertising. Rather than building everything in-house, organizations can buy a XaaS item permit for an all-inclusive period and exploit its broad foundation. However long the XaaS item is accessible, this can be rewarding. "Anything" is a general 
classification, which can at times make the idea of XaaS organizations challenging to get a handle on.

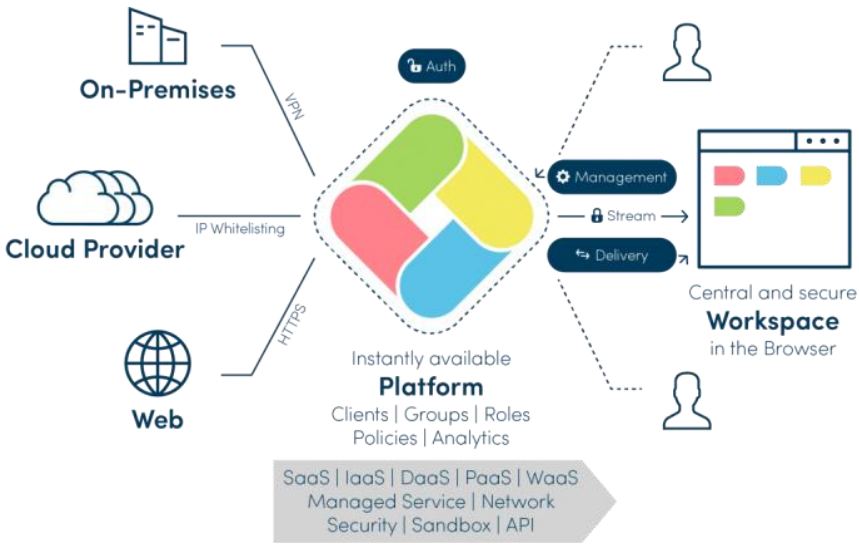

Fig.1 XaaS (Source: kinsta.com)

\section{SOME Classes of XAAS}

Since XaaS means "anything as an assistant," the rundown of models is unending. Numerous sorts of IT assets or administrations are presently conveyed along these lines. Comprehensively talking, there are three classes of distributed computing models, programming as assistance (SaaS), stage as a help (PaaS), and foundation as a help (IaaS). Outside these classes, there are different models, and they incorporate the accompanying:

- SaaS (Software as a Service): SaaS means "Programming as a Help," and it is the most widely recognized kind of XaaS business. Organizations incorporate SaaS items into their tech stack and utilize the product to smooth out business activities without fostering development without any preparation. At last, it's anything but an organization, both time and assets, empowering its individuals to focus on center business capacities. The typical organization utilizes 137 Saas applications, which is $30 \%$ higher than the earlier year. It shows how famous coordinated SaaS arrangements are with virtually every sort of organization. One remarkable SaaS organization is HubSpot, and across the board showcasing structure that capacities as inbound promoting, deals, and administration stage. A vast number of clients utilize this product to control their showcasing endeavors.

- PaaS (Platform as a Service): PaaS means "Platform as an Assistance." PaaS organizations offer clients a cloudbased arrangement that empowers them to make applications, programming, and other designing ventures on the stage as opposed to building their own. PaaS organizations can offer their clients everything going from workers to capacity, information base usefulness, and that's just the beginning. The stage is housed and wholly claimed by the organization. Clients can construct their items on this stage, removing the exorbitant costs of purchasing and putting away equipment autonomously. PaaS gives business visionaries and entrepreneurs an establishment to make items on the cloud-based framework and offer them to the majority.

- IaaS (Infrastructure as a Service): IaaS means "Infrastructure as a Service." IaaS organizations give a framework as organization-based arrangements and capacity. By and large, they offer registering ability to create, run, and scale items. On the off chance that a PaaS stage is the thing that an organization would use to fabricate their application or programming, an IaaS organization is the thing that they'd use to control and develop it. IaaS organizations ordinarily offer a "paymore only as costs arise" model, permitting clients to pay for whatever amount they use throughout a set time. One significant disadvantage is that you become entirely dependent on the IaaS organization since it basically makes up your organization's foundation.

- Analytics as a Service (AaaS): AaaS means "Analytics as a Service." Organizations are transforming information into bits of knowledge and utilizing those experiences to drive business choices. With a shift toward advanced arrangements, organizations are utilizing AaaS items to follow their crucial business measurements. The AaaS business was worth almost $\$ 5$ billion out of 2019. Specialists expect that it's anything but an accumulated pace of development of more than $25 \%$ through 2027. Organizations with a solid handle of the investigation will better position themselves for whatever deterrents they may confront.

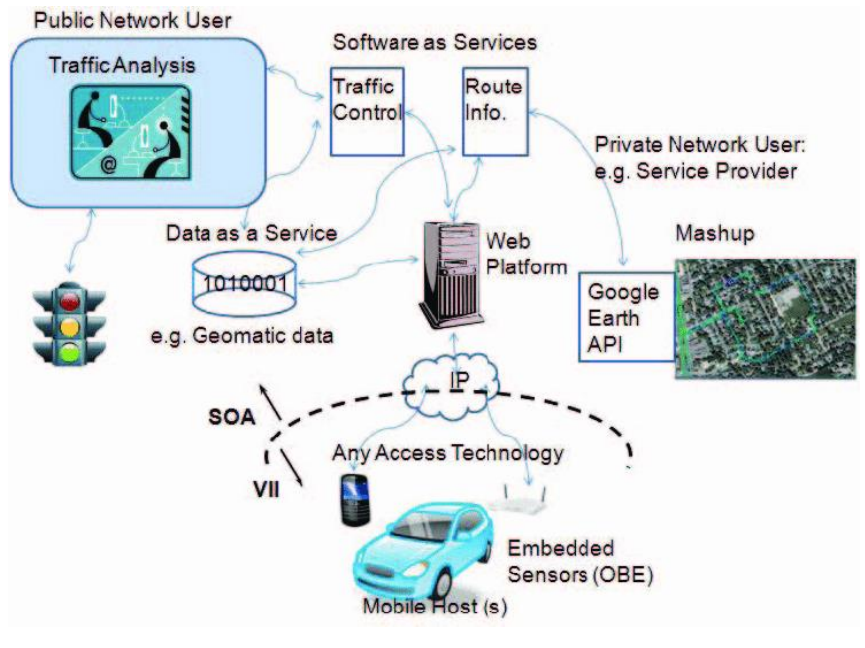

Figure: Daas (Source: researchgate.net)

- DaaS (Database as a Service): DaaS means "Work area as an Assistance." DaaS organizations empower clients to deal with their whole labor force through a safe internet browser. Representatives would separately sign into that program when revealing for work. This protected help makes it simple for workers to get to vital documents, projects, and programming-even while they're out of the workplace. As more organizations change to remote working, DaaS items 
are in expanding request. The DaaS market is required to develop to more than $\$ 10.7$ billion by 2023. DaaS items' adaptability and unwavering quality are substituting the requirement for organizations to assemble exclusively, limited work areas.

\section{AdvantAges OF XAAS}

They were improving the cost model. With XaaS, organizations can reduce expenses by buying administrations from suppliers on a membership premise. Before XaaS and cloud administrations, organizations needed to purchase singular items-programming, equipment, workers, security, and framework-introduce them on location, and afterward connect all that together to make organizations (Vadlamudi, 2018).

Here are five center advantages that $\mathrm{XaaS}$ offers its clients:

- Nimbleness: XaaS permits more modest organizations to present new arrangements all the more rapidly and access devices that would have been far off monetarily previously.

- Information Translation: Organizations presently don't have to depend on instinct to settle on business choices; in the truth of XaaS, there's simpler admittance to massive information instruments and bits of knowledge that take into account information investigation and understanding. This should be possible at a lower cost to settle on better-educated choices (Ganapathy, 2019).

- Usefulness: XaaS applications work with smoothed-out correspondence just as document sharing, notwithstanding regions like secret word and security the board. XaaS limits the time spent on support and eliminates the hindrances to scaling framework and the need to oversee workers (Vadlamudi, 2019).

- Decreased Expenses: The more organizations put resources into XaaS, the more they'll see massive expense decreases. Maybe then the significant expense of proprietorship for a particular arrangement, organizations eliminate the need to go "all in" on specific programming buy and pay for just the highlights and apparatuses they need.

- Network safety: Hardly any private ventures are set up to climate a digital assault, yet putting resources into XaaS gives the thorough digital protection front of innovation suppliers. Organizations can execute better verification and secret phrase arrangements and influence applications that ensure business and client information.

- Everything as an Assistance, or XaaS, permits private companies to pay for just what they use, eliminating the significant expense of equipment and programming possession and moving the focal point of the IT group back to organization destinations.

\section{What ARE THE DetRIMENTS OF XAAS?}

XaaS has some likely disadvantages: conceivable personal time, execution issues, and intricacy.

Conceivable personal time. The web at times breaks, and when it does, your XaaS supplier may have issues also. With XaaS, web dependability, flexibility, provisioning, and dealing with the framework assets can be issues. On the off chance that XaaS workers go down, clients will not have the option to utilize them. XaaS suppliers can ensure benefits through SLAs.

Execution issues. As XaaS turns out to be more famous, transfer speed, idleness, information stockpiling, and recovery times can endure. In the event that an excessive number of clients utilize similar assets, the framework can back off. Applications running in virtualized conditions can likewise confront impacts. There can be joining issues in these unpredictable conditions, including the continuous administration and security of various cloud administrations.

Complexity impacts. Pushing technology to XaaS can relieve IT staff of day-to-day operational headaches; however, if something does go wrong, it might be harder to troubleshoot. The internal IT staff still needs to stay current on the new technology. Costs for maintaining highperforming, robust networks can increase-although the overall cost savings of XaaS models are usually much greater. Nonetheless, some companies want to retain visibility into their XaaS service provider's environment and infrastructure. In addition, a XaaS provider that gets acquired discontinues a service or alters its roadmap can have a profound impact on XaaS users.

\section{What is Function as a Service (FaAS)}

Function as a Service (FaaS) is a classification of distributed computing administrations that gives a stage permitting clients to create, run, and oversee application functionalities without the intricacy of building and keeping up the framework normally connected with creating and dispatching an application.

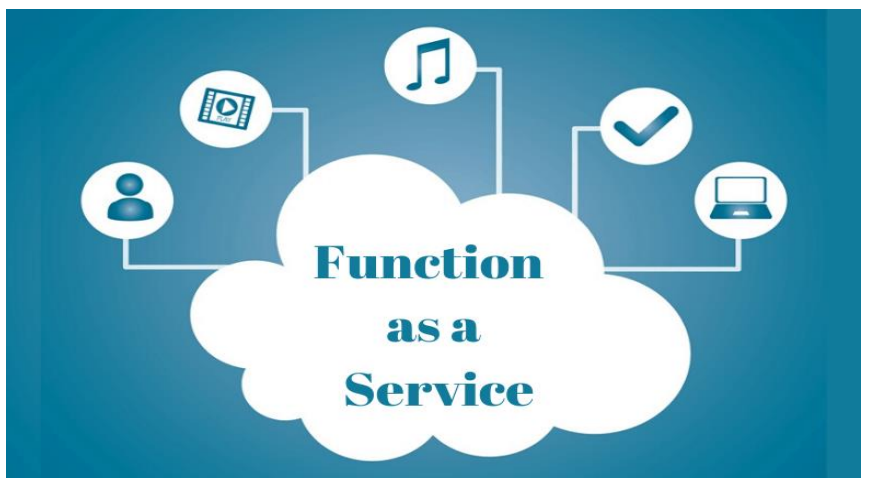

Figure: FaaS (Source: yourtechdiet.com)

Building an application following this model is one method of accomplishing a "serverless" design and is regularly utilized when building microservices 
applications (Ganapathy \& Neogy, 2017). FaaS was at first offered by different new businesses around 2010, like iCloud.

\section{Benefits of FaaS}

Here are some benefits associated with FaaS

- Improved engineer speed: With FaaS, engineers can invest more energy composing application rationale and less time agonizing over workers and conveys. This regularly implies a lot quicker advancement turnaround.

- Implicit adaptability: Since FaaS code is intrinsically adaptable, engineers don't need to stress over making high traffic or weighty use possibilities (Ganapathy \& Neogy, 2017). The serverless supplier will deal with the entirety of the scaling concerns.

- Cost proficiency: In contrast to conventional cloud suppliers, server-less FaaS suppliers don't charge their customers for inactive calculation time. Along these lines, customers just compensate for as much calculation time as they use and don't have to squander cash over-provisioning cloud assets.

\section{Shortcomings of FaaS}

- Less framework control: Hosting the third gathering oversee a piece of the foundation makes it intense to comprehend the entire framework and adds troubleshooting difficulties.

- Greater intricacy needed for testing: It very well may be hard to join FaaS code into a nearby testing climate, making exhaustive testing of an application a more concentrated errand.

\section{What IS IT AS A SERVICE}

IT as a Service (ITaaS) can be viewed as an extraordinary operational model that permits a line of business or client to burn through Data Innovation as an oversaw administration. The administrations are classified, permitting clients to burn-through and pay just for the administrations they require. Inner IT divisions or outside sellers can embrace this working model. From a client viewpoint, the experience of devouring ITaaS is like that of visiting a very good quality café that had some expertise in an assortment of cooking. A rich choice of menu things is very much listed with precise subtleties on valuing and fixings. They arranged things are conveyed in a precise amount inside sensible time. The visitor is just liable for devouring the food things. The related start to finish administrations, from securing crude things to cleaning the table for next visitors, is overseen by the specialist co-op, the café.

ITaaS works follow a comparative methodology: an assortment of administrations, design settings, system rules, and innovations are set accessible to address the remarkable expectations of every client and line of business. Customers have an assortment of decisions and can utilize IT arrangements arranged to satisfy the particular needs, which have effectively been evaluated and arranged for, however the ITaaS specialist co-op. They are not, at this point, the tech people zeroed in on extinguishing the fire when an end client neglects to utilize a necessary IT administration. All things being equal, it's centered on tending to the interesting prerequisites of interior purchasers, permitting them the choices to pick the best accessible assets and arrangements, alongside dealing with the whole experience lifecycle related to it.

\section{Benefits of ITaaS}

IT offices in huge undertakings ordinarily work as a solitary resource and specialist organization to a huge inner client base. With the ITaaS model, associations can utilize similar administrations without working an IT office in-house. This model is especially appropriate for SMB firms working on a restricted financial plan and assets. For huge ventures, interior IT offices can play the job of an ITaaS seller to inner clients and lines of business. This requires decoupling IT shops from the hierarchical construction, presenting new jobs and obligations, just as a social change in how IT interfaces and serves its inner clients.

\section{What IS InfRASTRUcture AS A SERVICE}

Infrastructure as a Service (IaaS) is a distributed computing administration that offers fundamental register, stockpiling, and systems administration assets on request, on a pay-more only as costs arise premise. IaaS is one of the four sorts of cloud administrations, alongside programming as a help (SaaS), stage as assistance (PaaS), and server less.

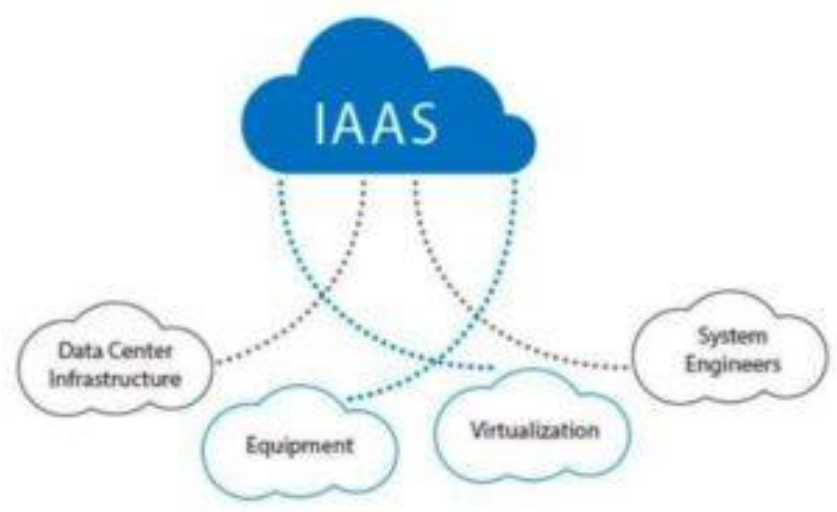

Figure: IaaS (Source: itedgenews.ng)

Relocating your association's framework to an IaaS arrangement assists you with diminishing upkeep of onpremises server farms, get a good deal on equipment expenses, and gain continuous business experiences. IaaS arrangements give you the adaptability to increase your IT assets and down with request. They additionally assist you with provisioning applications and increment the dependability of your fundamental foundation. IaaS allows you to sidestep the expense and intricacy of 
purchasing and overseeing actual workers and the datacenter framework. Every asset is offered as a different assistance segment, and you just compensation for a specific asset however long you need it.

\section{Benefits of IaaS}

- Diminishes capital uses and streamlines costs: IaaS wipes out the expense of designing and dealing with a physical data center, which settles on it a savvy decision for moving to the cloud. The pay-more only as costs arise membership models utilized by IaaS suppliers assist you with lessening equipment expenses and upkeep and empower your IT group to zero in on the center business.

- Expands scale and execution of IT jobs: IaaS allows you to scale worldwide and oblige spikes in asset interest. That way, you can convey IT assets to workers from any place on the planet quicker and upgrade application execution.

- Builds dependability, unwavering quality, and acceptability: With IaaS, there's no compelling reason to keep up and update programming and equipment or investigate gear issues. With the fitting understanding set up, the specialist co-op guarantees that your foundation is solid and meets administration level arrangements (SLAs).

- Improves business progression and catastrophe recuperation: Accomplishing high accessibility, business congruity, and calamity recuperation are costly on the grounds that it's anything but a lot of innovation and staff. Yet, with the right SLA set up, IaaS assists with diminishing this expense. It additionally assists you with getting to applications and information as a regular during a catastrophe or blackout.

\section{What IS Security As A Service (SECAAS)}

It's anything but a rethought administration wherein an external organization handles and deals with your security. At its generally fundamental, the easiest illustration of safety as assistance is utilizing an enemy of infection programming over the web (Vadlamudi, 2016). With security as a help, security arrangements are not, at this point conveyed locally, where your IT office introduces infection assurance programming, spam separating programming, and other security apparatuses on each machine or on the organization or worker in your work environment, staying up with the latest or advising them to utilize it (Paruchuri, 2019). The old method of doing things is likewise costly; you have forthright expenses for equipment just as proceeding with costs for licenses to permit you to utilize the product. Security as assistance permits you to utilize similar devices utilizing just an internet browser, making it immediate and reasonable.

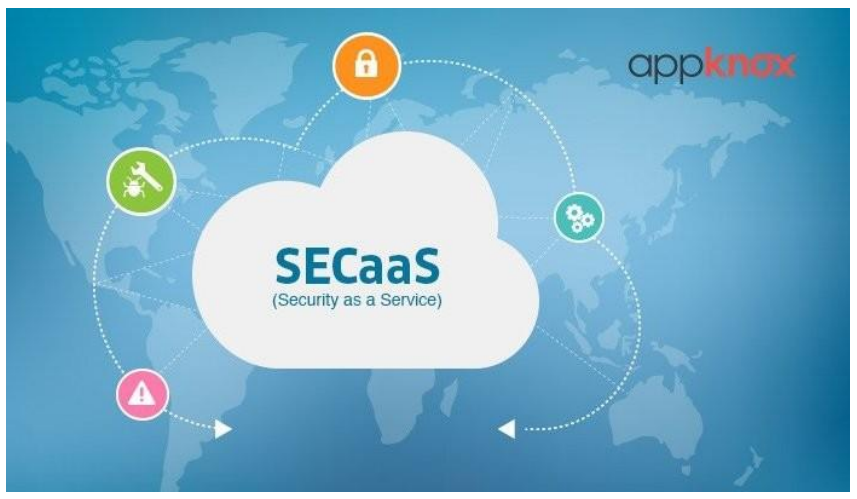

Figure: SECaas (Source: linkedin.com)

\section{Advantages OF Safety AS A Help}

There is a lot of benefits to utilizing security as an assistance offering. These include:

- You work with the most recent and most refreshed security devices accessible. For against infection apparatuses to be compelling and valuable, they need to work with the most recent infection definitions, permitting them to step out dangers, even the freshest ones. With security as assistance, you're continually utilizing devices that are refreshed with the most recent dangers and choices (Paruchuri \& Asadullah, 2018). This implies not no more stressing that your clients are not refreshing their enemy of infection programming and staying up with the latest to guarantee the most recent security patches are being used. A similar case goes for refreshing and keeping up spam channels.

- You get the best security individuals working for you. IT security specialists are available to your no matter what, and they may have more insight and a preferable range of abilities over anyone in your IT group.

- Quicker provisioning. The magnificence of as-aadministration contributions is that you can give your clients admittance to these devices in a flash. SECaaS contributions are given on request, so you can increase or down as the need emerges, and you can do as such with speed and nimbleness.

- You will zero in on what's more significant for your association. Utilizing a web interface or approaching an administration dashboard can make it simpler for your own IT group to manage and control security measures inside the association (Vadlamudi, 2017).

- Makes in-house executives less difficult. In the event that you have ensured information, it's anything but enough to simply keep it secure. You should know when a client gets to this information when the individual in question doesn't have any authentic business motivation to get to it.

- Save money on costs. You don't need to purchase equipment or pay for programming licenses. All things considered, you can supplant the forthright capital with variable working costs, normally at a limited rate contrasted with the forthright expenses. 


\section{WHAT TO LOOK FOR IN SECAAS PROVIDERS}

In case you're contemplating using the administrations of a SECaaS supplier, there are a couple of significant things to search for:

- Interoperable: Stay away from merchant lock-in and have greater adaptability by ensuring that the arrangements you pick have no interoperability issues.

- Low TCO: The Total Cost of Ownership (TCO) is a decent basis in picking a SECaaS supplier. Peruse the fine print and be certain that you get the language right, or, in all likelihood, you may wind up paying more with your picked bundle than a comparable one with an ostensibly higher publicized rate.

- Detailing: Your picked arrangements ought to have a revealing system that would permit you to see significant security occasions, assault logs, and other significant information. While the essential advantage of SECaaS is hosting the third get-together to deal with the full security picture, you actually need the perceived alternative. Security as a Help is turning into an undeniably mainstream choice among ventures and SMBs the same. The developing reception of SECaaS is driven by a lack of safety assets - including qualified infosec experts just as abilities and apparatuses in general - combined with the steadily growing danger scene. For some organizations, today, re-appropriating the administration, execution, and oversight of the unpredictable domain of safety basically bodes well, and it's anything but a savvy venture for organizations that exploit it (Ganapathy, 2018).

\section{What is DataBase as a Service}

Database as a Service (DBaaS) is a distributed computing overseen administration offering that gives admittance to a data set without requiring the arrangement of actual equipment, the establishment of programming, or the need to design the data set. Most support and managerial undertakings are taken care of by the specialist organization, opening up clients to rapidly profit by utilizing the data set. In a standard registering climate, the information base worker is important for the on-premises processing framework and is introduced, overseen, and arrived behind schedule by an association's IT staff.

\section{Database as a Service}
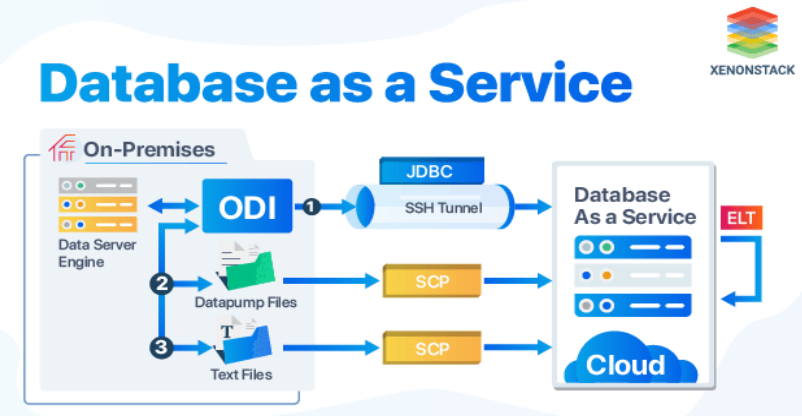

Figure: DBaaS (Source: xenonstack.com)

\section{DBaaS Model}

The DBaaS model is ideal for little to medium-sized organizations that don't have all-around staffed IT divisions. Offloading the assistance and upkeep of the data set to the DBaaS supplier empowers little to medium-sized organizations to execute applications and frameworks that they, in any case, couldn't bear to assemble and uphold onpremises. Responsibilities including information with tough administrative necessities may not be reasonable for a DBaaS model. Besides, crucial applications requiring ideal execution and $99.999 \%$ uptime might be more qualified for on-premises execution.

\section{Benefits}

Contrasted with conveying an information base administration framework on-premises, DBaaS offers your association huge monetary, operational, and key advantages:

- Cost reserve funds: Setting down the framework for data set administration is costly (Paruchuri, 2017); scaling it depending on the situation is exorbitant and regularly inefficient. With DBaaS, your association pays an anticipated occasional charge dependent on the assets you burn through-there's no compelling reason to buy the extra ability to have available for speculative future requirements (Paruchuri, 2018).

- Adaptability-here and there: You can rapidly and effectively arrange extra stockpiling and figuring limit at run time in the event that you need it, and you can downsize your data set group during non-top utilization times to save cost.

- Easier, less exorbitant administration: To oversee and keep a data set on-premises, you'd need an in-house managerial group. With DBaaS, the cloud supplier oversees everything (despite the fact that you can decide to deal with specific viewpoints on the off chance you wish). DBaaS eases up the regulatory weight on your current IT staff and liberates them to deal with applications and development.

- Rapid improvement and quicker an ideal opportunity to showcase: With an on-premises information base framework, advancement groups ordinarily need to demand access through IT, an interaction that can require days or weeks. Conversely, with DBaaS, designers can grab information base capacities and twist up and arrange a data set that is prepared to incorporate with their application in minutes.

- Information and application security: Cloud data set suppliers ordinarily offer endeavor grade security, including highlights like default encryption of information very still and on the way and coordinated character and access the executive's controls (Ganapathy, 2016). Some additionally fulfill explicit administrative consistency guidelines.

- Diminished danger: DBaaS contributions from significant cloud suppliers commonly incorporate an assistance level understanding (SLA), ensuring a 
specific measure of uptime. On the far-fetched occasion that your supplier doesn't meet the prerequisites specified in the SLA, you'll be made up for any abundance vacation you experience.

- Programming quality: The significant cloud suppliers offer a wide assortment of exceptionally configurable DBaaS choices. Each preselected for quality, so you will not need to stress over the swimming through various data sets (Neogy \& Paruchuri, 2014)

\section{CONCLUSION}

These services are geared towards product optimization and improved client or consumer engagement by showcasing how they can improve marketing. These tools, upon proper utilization, no doubt save a lot of resources for the management and reduce their security vulnerability on their respective platforms as the case may be.

\section{References}

Ganapathy, A. (2016). Blockchain Technology Use on Transactions of Crypto Currency with Machinery \& Electronic Goods. American Journal of Trade and Policy, 3(3),

115-120. https://doi.org/10.18034/ajtp.v3i3.552

Ganapathy, A. (2016a). Virtual Reality and Augmented Reality Driven Real Estate World to Buy Properties. Asian Journal of Humanity, Art and Literature, 3(2),

137-146.

https://doi.org/10.18034/ajhal.v3i2.567

Ganapathy, A. (2018). Cascading Cache Layer in Content Management System. Asian Business Review, 8(3), 177182. https://doi.org/10.18034/abr.v8i3.542

Ganapathy, A. (2019). Image Association to URLs across CMS Websites with Unique Watermark Signatures to Identify Who Owns the Camera. American Journal of Trade and Policy, 6(3), 101-106. https://doi.org/10.18034/ajtp.v6i3.543

Ganapathy, A. (2019a). Mobile Remote Content Feed Editing in Content Management System. Engineering International, 7(2), 85-94. https://doi.org/10.18034/ei.v7i2.545

Ganapathy, A., \& Neogy, T. K. (2017). Artificial Intelligence Price Emulator: A Study on Cryptocurrency. Global
Disclosure of Economics and Business, 6(2), 115-122. https://doi.org/10.18034/gdeb.v6i2.558

Neogy, T. K., \& Paruchuri, H. (2014). Machine Learning as a New Search Engine Interface: An Overview. Engineering International, 2(2), 103-112. https://doi.org/10.18034/ei.v2i2.539

Paruchuri, H. (2017). Credit Card Fraud Detection using Machine Learning: A Systematic Literature Review. ABC Journal of Advanced Research, 6(2), 113-120. https://doi.org/10.18034/abcjar.v6i2.547

Paruchuri, H. (2018). AI Health Check Monitoring and Managing Content Up and Data in CMS World.Malaysian Journal of Medical and Biological Research, 5(2), 141-146. https://doi.org/10.18034/mjmbr.v5i2.554

Paruchuri, H. (2019). Market Segmentation, Targeting, and Positioning Using Machine Learning. Asian Journal of Applied Science and Engineering, 8(1), 7-14. Retrieved from https://journals.abc.us.org/index.php/ajase/article/ view $/ 1193$

Paruchuri, H., \& Asadullah, A. (2018). The Effect of Emotional Intelligence on the Diversity Climate and Innovation Capabilities. Asia Pacific Journal of Energy and Environment, 5(2), 91-96. https://doi.org/10.18034/apjee.v5i2.561

Vadlamudi, S. (2016). What Impact does Internet of Things have on Project Management in Project based Firms?. Asian Business Review, 6(3), 179-186. https://doi.org/10.18034/abr.v6i3.520

Vadlamudi, S. (2017). Stock Market Prediction using Machine Learning: A Systematic Literature Review. American Journal of Trade and Policy, 4(3), 123128. https://doi.org/10.18034/ajtp.v4i3.521

Vadlamudi, S. (2018). Agri-Food System and Artificial Intelligence: Reconsidering Imperishability. Asian Journal of Applied Science and Engineering, 7(1), 33-42. Retrieved from https://journals.abc.us.org/index.php/ajase/article/view/1192

Vadlamudi, S. (2019). How Artificial Intelligence Improves Agricultural Productivity and Sustainability: A Global Thematic Analysis. Asia Pacific Journal of Energy and Environment, 6(2), 91-100. https://doi.org/10.18034/apjee.v6i2.542 
Archive Link:

https://abc.us.org/ojs/index.php/ajtp/issue/archive 